\title{
Index of Mannheim and mortality in sepsis abdominal
}

\author{
Índice de Mannheim y mortalidad en sepsis abdominal
}

Luis G. González-Pérez', Yazmín Sánchez-Delgado², Ansony R. Godínez-VidaR*, José F. Cruz-Manzano², Gabriela E. Gutiérrez-Uvalle ${ }^{1}$ and Noé I. Gracida-Mancilla ${ }^{1}$

${ }^{1}$ Sepsis Clinic, General Surgery Department; ${ }^{2}$ General Surgery Department. General Hospital de México Dr. Eduardo Liceaga, Mexico City,

\begin{abstract}
Background: Abdominal sepsis represents the host's peritoneal inflammatory response to microbial invasion, which may be mild or severe, depending on the degree of contamination of the peritoneal cavity; with a reported mortality of $17 \%$ : The Mannheim peritonitis index is a clinical tool and a predictor of mortality in patients with peritonitis, with high sensitivity and specificity. Objective: To determine if there is a correlation between the score obtained by the Mannheim peritonitis index, and mortality, in patients with abdominal sepsis. Method: A retrospective, observational, cross-sectional study, during, the period between July 2013 and January 2014, in patients diagnosed with abdominal sepsis, attended at the General Hospital of Mexico Dr. Eduardo Liceaga. Results: We included 177 cases, 85 of the female sex and 92 of the male sex. The average age was 43 years. The most common organ responsible for abdominal sepsis was the appendix. Mortality of 18 cases (10.3\%). The cases were divided, according to the Mannheim index, in mild cases ( $<25$ points) and severe case ( $>26$ points). Of 27 severe cases, 8 (29.6\%) died, while of the 150 mild cases 10 (6.7\%) died (odds ratio: 5.895; 95\% confidence interval: 2:07116.77; $p<0.05$ ). Conclusions: The Mannheim scale is a good predictor of mortality for patients with abdominal sepsis.The optimal cut-off point is 20.
\end{abstract}

KEY WORDS: Abdominal sepsis. Mortality. Mannheim peritonitis index.

\section{Resumen}

Introducción: La sepsis abdominal representa la respuesta inflamatoria peritoneal ante la invasión microbiana, con una Mnortalidad del $17 \%$. El índice de peritonitis de Mannheim es una herramienta clínica y un predictor de mortalidad, con altasensibilidad y especificidad. Objetivo: Determinar si existe correlación entre el puntaje obtenido mediante el índice de peritônitis de Mannheim y la mortalidad. Método: Estudio retrospectivo, observacional, transversal, durante el periodo entre julio de 2013 y enero de 2014, en pacientes con diagnóstico de sepsis abdominal, en el Hospital General de México Dr. Eduardo Liceaga. Resultados: Se incluyeron 177 casos, 85 de sexo femenino y 92 de sexo masculino. La edad media fue de 43 años. El órgano causante de la sepsis abdominal más frecuente fue el apéndice. Fallecieron 18 pacientes (10.2\%). Se dividieroß los casos, de acuerdo con el índice de Mannheim, en leves (< 25 puntos) y graves (> 26 puntos). De 27 pacientes graves, fallecieron 8 (29.6\%), mientras que de los 150 leves fallecieron 10 (6.7\%) (odds ratio: 5.895; intervalo de confianza del 95\%: 2.071-16.77; $p<0,05)$. Conclusión: El índice de Mannheim es un buen predictor de mortalidad para los pacientes con sepsis abdominal. El punto de corte óptimo es 20.

PALABRAS CLAVE: Sepsis abdominal. Mortalidad. Índice de peritonitis de Mannheim.

Correspondence:

*Ansony Roger Godínez-Vidal

Balmis 148, Col. Doctores. Del Cuauhtémoc

C.P.06726, Mexico City, Mexico

E-mail: ansony.rgv.@gmail.com
Date of reception: 04-03-2018

Date of acceptance: 04-05-2018

DOI: $10.24875 / C I R U E . M 18000064$
Cir Cir. 2018;86:372376

Contents available at PubMed www.cirugiaycirujanos.com 


\section{Background}

Peritonitis is defined as inflammation of the serous membrane that delimits the abdominal cavity and the organs therein contained. Peritoneal cavity infection can occur through several routes: "spontaneous", which mainly occurs through hematogenous dissemination; the infection that is introduced to the peritoneal cavity, predominantly observed in patients on peritoneal dialysis and that is also susceptible to treatment only with antibiotics, is called primary peritonitis; tertiary peritonitis refers to persistent or recurrent peritoneal infection that usually occurs in critical patients with secondary peritonitis, when the host defenses and antimicrobial therapy have failed and superinfection by resistant organisms, usually gram-negative bacilli or fungi, occurs; secondary peritonitis will have a clinical presentation with acute abdomen, and its diagnosis and initial treatment will necessarily be surgical; and the third route of infection of the peritoneal cavity is due to leakage of intestinal contents into it, it is polymicrobial by nature and occurs as generalized peritonitis (secondary peritonitis) or as a localized abscess ${ }^{1}$.

Abdominal sepsis is the systemic response to an initially localized infectious process, represents the non-specific peritoneal inflammatory host response in the presence of microbial invasion and manifests itself with systemic symptoms such as fever, tachycardia, hypotension, tachypnea, leukocytopenia or leukocytosis, and high cardiac output; in severe cases, it can cause an important alteration of systemic perfusion with multiple organ failure ${ }^{2}$.

\section{Mortality in secondary peritonitis}

Peritoneal infection and inflammation generate a complex systemic response that can be mild or serious, depending on the degree of contamination of the peritoneal cavity. This generalized inflammatory response generates vascular, cellular, immune and metabolic changes that, if persistent, can elicit ischemic effects at different places and trigger different organ failures (kidney, liver, lung, cardiovascular, etc. failure). The mortality rate generated by the main causes of secondary peritonitis has not changed in the last two decades, with mortality being reported at $17 \%^{3}$. In addition, overall mortality reported for appendicitis is $1 \%$, and it increases up to $5 \%$ when there is perforation, with most deaths occurring in elderly patients. The most important prognostic factors in emergency colorectal surgery are preoperative status, advanced age and presence of fecal peritonitis, which together have a mortality rate of up to $60 \%{ }^{4}$.

\section{Predictors of mortality in surgery}

Different biomarkers and functional scales have been developed to predict morbidity and mortality in surgical patients. With no doubt, the most widely studied disease-severity physiological scoring model is Acute Physiology and Chronic Health Evaluation II scale (APACHE II) ${ }^{5}$, which is constructed taking the worst value obtained within the first 24 hours after admission based on 12 variables, with ponts added for age and chronic health, yielding a total score that ranges from 0 to 71 . The APACHE II scale has bêen validated in various studies on surgical and non-surgical patients in intensive care units, with a mean score from 9 to 15 being observed among survivors and an average of 15 to 25 points among those who $\operatorname{died}^{6}$. With patients with secondary peritonitis being assessed with scores ranging from 11 to $15, \mathrm{APA} \overline{\mathrm{C}} \mathrm{HE}$ II has shown a sensitivity of $100 \%$ and specificity of $73.8 \%$ to predict mortality, and in the group of patients with scores between 16 and 20, it has shown a sensitivity of $87.5 \%$ and specificity of $100 \%^{7.8}$.

\section{Mannheim peritonitis index}

Mannheim Peritonitis Index (MPI) (Table 1) is a mortality predictor created in Germany by Wacha and Linder, which was based on the result of 1,2539patients with peritonitis, developed by discriminant analysis of 17 possible risk factors, out of which eight were significant in terms of prognostic value. It allowsimmediate classification in two groups: low and high mortality. The prognostic factors it includes are age, gender, organ failure, presence of cancer, colonicorigin of contamination, generalized peritonitis and peritoneal fluid characteristics (citrine, purulent or fecal), with different numerical factors being assignedfaccording to whether the results are favorable or adverse. A 0 to 47 score is obtained, with a cutoff point of 26 , by means of which a mortality of $50 \%$ was established in patients, and in those with scores lower than 26 , only $1-3 \%$, with a sensitivity of $95.9 \%$ and specificity of $80 \%$, positive predictive value of $98.9 \%$ and negative predictive value of $50 \%$. Due to the lärge difference between both groups' prognosis, others have considered establishing three prognostic groups, with cutoff scores between them of less than 21 
Table 1. Mannheim peritonitis index

\begin{tabular}{lc}
\hline Risk factor & Value if present \\
\hline Age $>50$ years & 5 \\
Female gender & 5 \\
Organ failure & 7 \\
Cancer & 4 \\
Peritonitis duration $>24 \mathrm{~h}$ & 4 \\
Non-colonic origin sepsis & 4 \\
Generalized diffuse & 4 \\
peritonitis & \\
Clear exudate & 0 \\
Citrine-purulent & 6 \\
Fecal & 12 \\
\hline
\end{tabular}

points, from 21 to 29 points and higher than 29 points, and mortality rates of $2.3,22.5$ and $59.1 \%$, respectively; sensitivity and specificity are similar to those established for the groups with a 26-point cut-off9-13.

Abdominal sepsis due to secondary peritonitis is a common, serious condition with high mortality potential. There are useful tools to predict mortality of the patient with peritonitis, but a large part of them is based on biochemical parameters or uses calculators or special electronic systems for their application. MPI is a clinical tool that has been suggested as a mortality predictor in patients with peritonitis, and has been shown to be a highly useful, simple, highly sensitive and specific tool that is composed of clinical variables and trans-operative findings.

The purpose of this study was to determine if there is correlation between the MPI-obtained score and mortality in patients with abdominal sepsis due to secondary peritonitis who required surgical management.

\section{Method}

Retrospective, observational, cross-sectional study of patients treated at General Hospital of Mexico "Dr. Eduardo Liceaga" during the period between July 2013 and January 2014, who had been diagnosed with acute abdominal pain and in whom abdominal sepsis due to secondary peritonitis was found during surgery.

\section{Results}

The sample is composed of 177 cases, $85(48 \%)$ of the female gender and $92(52 \%)$ of the male gender.
Table 2. Classification by severity

\begin{tabular}{lll}
\hline Severity indicator & Mild & Severe \\
\hline APACHE II & $<14$ & $>25$ \\
Mannheim peritonitis index & $<15$ \\
\hline & & $>-26$ \\
\hline
\end{tabular}

Average age was 43.38 years. The most common organ causative of abdominal sepsis was the appendix, followed by the gallbladder, small intestine-and colon. Among the entire sample, there was $10 \%$ of mortality.

The cases were divided, according to the MPI score (Table 2), into mild (<25 points; 150 patients, $84.8 \%$ ) and severe (> 26 points; 27 patients, 15.2\%). When the cases were divided according to APACHE II scaleassessed severity, 42 cases (23.7\%) were found tio be severe and $135(76.3 \%)$ were mild.

Of the 27 patients classified in the severe group according to MPI, eight died $(29.6 \%)$, while of the 150 patients classified in the mild group according to MPI, 10 died (6.7\%), and when the chi-squared statistic is applied to these observations a $p$-value $<0.05$ is obtained (odds ratio: $5.895 ; 95 \%$ confidence interval: 2.071-16.77).

When the ROC curve for MPI was analyzed with regard to its relationship with mortality, we obtained an area under the curve of 0.84 , with a cutoff point of 20 , for a sensitivity of $83 \%$ and specificity of $77 \%$ (Fig. 1).

\section{Discussion}

Abdominal sepsis due to secondary peritonitis is a pathology with high mortality and economic costs due to prolonged hospital stay and the therapeutics used at the intensive therapy unit. The importance ofothe systemic inflammatory response syndrome secondary to abdominal pathology can show evidence of organ failure limited to one or two organs or develop anexaggerated inflammatory response that rapidly progresses to death, few days after initial trauma, secondary to multiple organ failure ${ }^{14}$. Mortality with multiple organ failure is proportional to the number of systems involved and ranges from $30 \%$ with single organ faiture to $100 \%$ with five compromised organs $\mathrm{s}^{15}$.

Various studies have devised scoring systems to. dict morbidity and mortality in emergency surgery.'The APACHE II score is used in the intensive care unit and requires 12 physiological parameters over a 24-hour period to be calculated and, for this reason, usingit in 


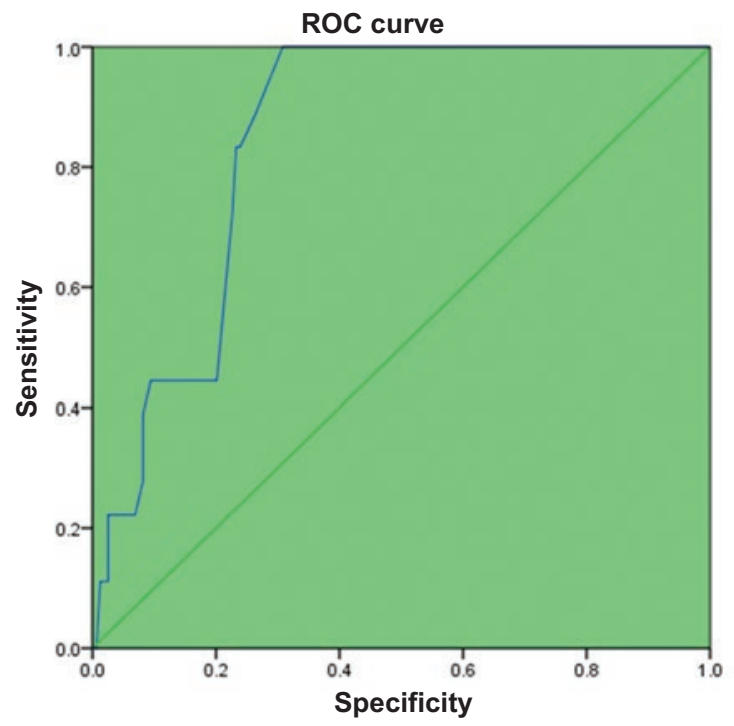

The diagonal segments are generated by ties

Figure 1. Area under the curve of 0.84 , with a cutoff point of 20 , for a sensitivity of $83 \%$ and specificity of $77 \%$.

emergency surgery is not possible. In patients with surgical pathology due to abdominal sepsis, in addition to the APACHE II score other systems have been developed, such as MPI, the multiple organ failure score and the sepsis score $^{16}$. In comparative studies, the APACHE II scale and MPI offer a better prediction of mortality in patients with abdominal sepsis. The combination of MPI and APACHE II improves specificity, but they are mainly used when assessing the outcomes of surgical patients admitted to intensive care units after surgery. MPI is simple to calculate and useful in the prediction of mortality, with a sensitivity of $83 \%$ and specificity of $77 \%$. In our study, we analyzed the MPI using a standardized international cutoff point, and our result corroborates that MPI directly correlates with mortality in our sample. When this result was obtained, we plotted a ROC curve in order to have a better discrimination point to determine mortality, and this curve reports a score of 20 points with an area under the curve larger than 80 , sensitivity of $83 \%$ and specificity of $77 \%$. Thus, we can assume that the higher the MPI score, the higher the mortality (Fig. 2). This result will be taken into consideration in future prospective studies in order to standardize our cutoff point.

Currently, secondary peritonitis is common in general surgery. After initial laparotomy, the doubt arises regarding a second intervention due to patient postsurgical evolution. There are parameters, such as heart rate, hemoglobin, body temperature, presence of bowel movements, the extent of contamination at

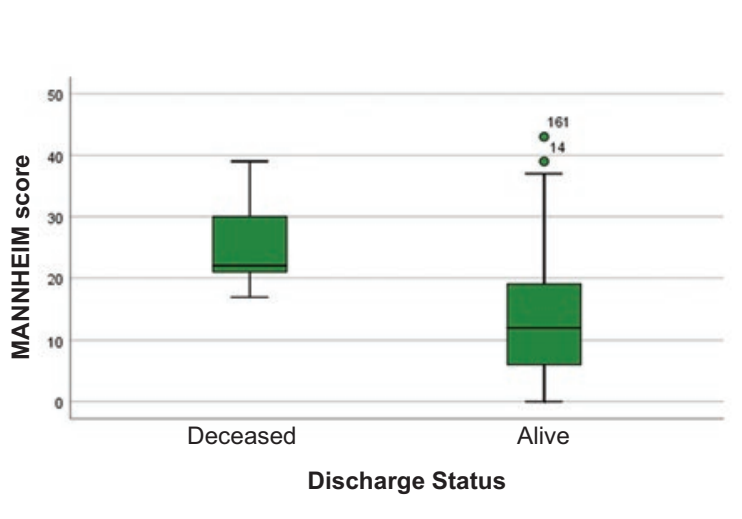

Figure 2. The higher the Mannheim index score, the highes the mortality.

first surgery and the need of inotropics, which increase the risk of a second intervention. Howeve 5 an ideal mortality scale that is accurate, easy to calculfate and reproducible, both in the preoperative and postoperative periods, and that allows assessing the response to the surgical management employed, chas not yet been designed.

\section{Conclusion}

MPI is a good mortality predictor for patients with abdominal sepsis due to secondary peritonitis. In our population, the optimal cutoff point to determine the severity of abdominal septic patients using the MPI is 20 points.

\section{Funding}

No funding from any company was obtained.

\section{Conflicts of interests}

There are no conflicts of interest.

\section{References}

1. Townsend Jr CM, Beauchamp RD, Evers BM, Mattox KL. Sabiston Textbook of Surgery. $18^{\text {th }}$ ed. Philadelphia: WB Saunders. 2008.

2. Carrillo-Esper R, Carrillo-Córdova JR, Carrillo-Córdova LD. Estudio epidemiológico de la sepsis en unidades de terapia intensiva mexicanas. Cir Cir. 2009;77(4).

3. Pulido Cejudo A. FACS. Tratamiento médico en sepsis abdominal. Infección en cirugía. Cirujano General. 2011;33(Supl 1).

4. Dombrovskiy VY, Martin AA, Sunderram J, Paz HL. Rapid increase in hospitalization and mortality rates for severe sepsis in the United States: a trend analysis from 1993 to 2003. Crit Care Med. 2007;35:1244

5. Sánchez Velázquez LD, Reyes Sánchez ME, D’Ector Lira DM, Bonilla Rivera LC, González González A, Magdaleno Padilla ML, et al. Discriminación y calibración de cuatro escalas de calificación del síndrome de disfunción orgánica múltiple. Estudio multicéntrico. Rev Asoc Mex̄Med Crit y Ter Int 2001;15(3):80-86.

6. Pardo Cabello AJ, Bermudo Conde S, Manzano Gamero MV. Prevalencia y factores asociados a desnutrición entre pacientes ingresados en un hospital de media-larga estancia. Nutr Hosp. 2011;26:369-75.

7. John MA, Bohnen MD, Mustard RA, Oxholm SE, Schouten BD. APACHE II Score and Abdominal Sepsis A Prospective Study, RN Arch Surg. 1988;123(2):225-22 
8. Vincent JL and Moreno R. Clinical review: Scoring systems in the critically ill. Critical Care 2010, 14:207.

9. Mesejo Arizmendi A, Blasco Cortés ML, Gabaldón Coronado J. Manua básico de nutrición clínica y dietética. Hospital Clínico Universitario de Valencia; 2000. p. 17-8.

10. Kreger BE, Craven DE, McCabe WR. Gram-negative bacteremia. IV Re-evaluation of clinical features and treatment in 612 patients. Am J Med. 1980;68:344.

11. Planas Vilá M, Montejo JC. Metodología aplicada en la valoración de estado nutricional. Libro blanco de la desnutrición clínica en España. Fundación Española de la Nutrición (FEN). 2013.

12. Bauer J, Capra S. Comparison of a malnutrition-screening tool with subjective global assessment in hospitalized patients with cancer: sensitivity and specificity. Asia Pac J Clin Nutr. 2003;12:257-60.
13. Sharma R, Ranjan V, Jain S, Joshi T, Tyagi A, Chaphekar R, A prospective study evaluating utility of Mannheim peritonitis index in predicting prognosis of perforation peritonitis. J Nat Sci Biol Med. 2015;6(Suppl 1):49-S52.

14. Sharma R, Ranjan V, Jain S, Joshi T, Tyagi A, Chaphekar R. A prospective study evaluating utility of Mannheim peritonitis index in predicting prognosis of perforation peritonitis. J Nat Sci Biol Med. 2015;6(Suppl1):S49-52

15. Salamone G, Licari L, Falco N, Augello G, Tutino R, Campanella S, et al. Mannheim Peritonitis Index (MPI) and elderly population: prognostic evaluation in acute secondary peritonitis. G Chir. 2016;37:243-9. ()

16. Muralidhar VA, Madhu CP, Sudhir S, Srinivasarangan M. Efficacy of Mannheim Peritonitis Index (MPI) score in patients with secondary peritonitis. J Clin Diagn Res. 2014;8:NC01-3. 